\title{
communications chemistry
}

COMMENT

https://doi.org/10.1038/s42004-021-00483-5

\section{Open questions on the reactivity of Criegee intermediates}

\author{
Rebecca L. Caravan (iD ${ }^{1}$, Michael F. Vansco (iD ${ }^{1} \&$ Marsha I. Lester (iD ${ }^{2 凶}$
}

Criegee intermediates are reactive intermediates formed in Earth's atmosphere through ozonolysis of alkenes. Here the authors outline the fundamental chemistry that influences their highly conformer- and substituent-dependent unimolecular and bimolecular reactivity, and discuss open questions of fundamental and atmospheric interest.

Criegee intermediates (CIs) are carbonyl oxide reactive intermediates with zwitterionic character that are formed from the ozonolysis of unsaturated hydrocarbons. Until recently ${ }^{1}$, direct generation and detection of these short-lived intermediates had not been realized, and thus our understanding of CI reactivity was based on careful analysis of complex steady state chamber studies. It was these experiments that first identified the potentially important role that CIs could play in Earth's lower atmosphere, e.g., the formation of sulfate aerosols in the troposphere from alkene ozonolysis in the presence of $\mathrm{SO}_{2}{ }^{2,3}$. Recent alternative methods for generation of CIs using diiodo-alkane and -alkene precursors facilitated direct detection, characterization, and kinetic studies of CIs in the laboratory ${ }^{1,4}$. These new studies revealed the structural and conformational dependence of CI reactivity, highlighting the importance of direct experimental and high-level theoretical studies to complement steady-state chamber investigations representing complete reaction sequences.

Significant efforts have been made to understand the reactivity of the three isoprene-derived CIs (formaldehyde oxide, $\mathrm{CH}_{2} \mathrm{OO}$; methyl vinyl ketone oxide, MVK-oxide; and methacrolein oxide, MACR-oxide; see Fig. 1 for chemical structures) motivated by both atmospheric pertinence and fundamental chemical interest. Isoprene is the most abundant non-methane hydrocarbon emitted into the atmosphere (ca. $600 \mathrm{Tg} / \mathrm{year})^{5}$. It is a five-carbon, conjugated diene, which is released into Earth's troposphere by trees and plants. Ozonolysis is an important sink of tropospheric isoprene $(\sim 10 \%)$ and results in the production of both one- and four-carbon CIs ${ }^{6}$. The vast predicted and observed differences in their unimolecular and bimolecular reactivity, despite their common origin and, for a subset of these, minimal structural differences, make these species particularly interesting from a fundamental standpoint ${ }^{7-9}$. Their remarkably different reactivity is illustrated in Fig. 1 utilizing known or predicted rate constants and concentrations for the primary atmospheric reactants (water vapor, $\mathrm{SO}_{2}$, and organic acids) from the Amazon region $1,7,8,10-14$. In this Comment, we discuss recent findings from direct studies of these isoprene-derived CIs, focusing on the four-carbon unsaturated CIs. We present some open, fundamental questions for future CI studies, and consider how these studies could contribute to understanding of real-world phenomena.

\section{Reactivity of the simplest Criegee intermediate}

$\mathrm{CH}_{2} \mathrm{OO}$ is formed with a $58 \%$ yield in isoprene ozonolysis ${ }^{6} . \mathrm{CH}_{2} \mathrm{OO}$ has been the subject of numerous experimental and theoretical studies since $2012^{1}$, when it was directly generated with sufficiently high yields to facilitate direct spectroscopic, kinetic and mechanistic characterization. The experimental work revealed that $\mathrm{CH}_{2} \mathrm{OO}$ reacts with $\mathrm{SO}_{2}$ at a rate 10,000

\footnotetext{
${ }^{1}$ Chemical Sciences and Engineering Division, Argonne National Laboratory, Lemont, IL, USA. ${ }^{2}$ Department of Chemistry, University of Pennsylvania,
} Philadelphia, PA, USA. ${ }_{\text {email: milester@sas.upenn.edu }}$ 


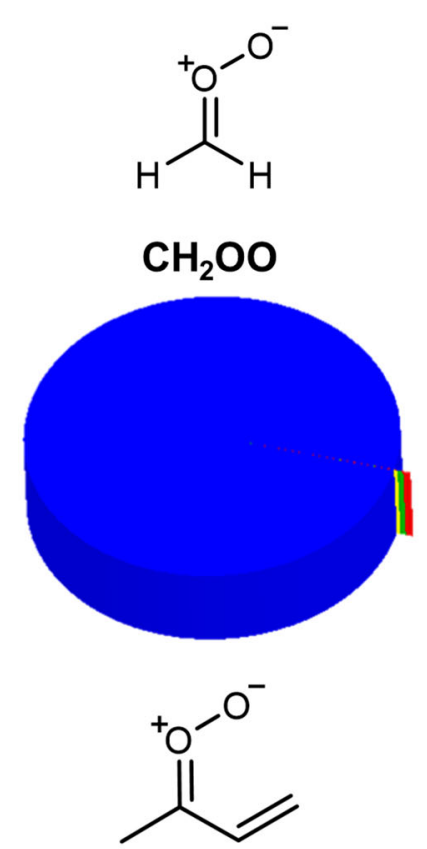

\section{anti-MVK-oxide}
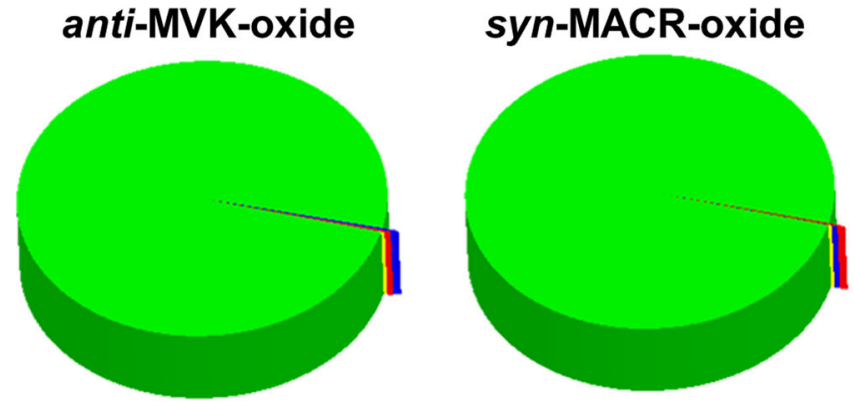

\section{Unimolecular decomposition of four-carbon unsaturated Criegee intermediates}

The four-carbon unsaturated CIs, MVK-oxide and MACR-oxide, are generated with yields of 23 and $19 \%$, respectively, in isoprene ozonolysis $^{6}$. MVK-oxide and MACR-oxide are isomers, both having vinyl and methyl substituents, but differing in the position of the methyl groups. Both have extended conjugation across the vinyl and carbonyl oxide groups that fundamentally changes their electronic structure and impacts their unimolecular and bimolecular chemistry in the atmosphere $8,12,17$. MVK-oxide and MACR-oxide each have four conformational forms with similar ground state energies (within ca. $3 \mathrm{kcal} \mathrm{mol}^{-1}$ ); the four conformers fall into two groups, separated by high barriers $(\sim 30 \mathrm{kcal}$ $\mathrm{mol}^{-1}$ for MVK-oxide ${ }^{8}$ ), which are distinguished by the orientation of the terminal oxygen with respect to the vinyl group (syn and anti) $)^{8,17}$. Under atmospheric conditions, the two conformers within each group (cis and trans) rapidly interconvert by rotation about the C-C bond ${ }^{12}$. Quite amazingly, the distinct conformational forms of MVK-oxide and MACR-oxide undergo remarkably different unimolecular decay processes with rates that differ by orders of magnitude ${ }^{7,8}$.

The syn conformers of MVK-oxide undergo slow thermal unimolecular decay $\left(33 \mathrm{~s}^{-1}\right)$ to $\mathrm{OH}$ radical products (Fig. 2) $)^{8}$. The relatively slow decay rate compared to simple alkyl-substituted CIs is attributed to the loss of extended conjugation and the resultant higher transition state barrier for unimolecular decay. By contrast, thermalized anti-conformers of MVK-oxide and analogous structural conformers of MACR-oxide undergo a unique decay mechanism with extremely rapid $\left(2140 \mathrm{~s}^{-1}\right.$ and $2500 \mathrm{~s}^{-1}$, respectively) ring closure to form dioxoles, 5 -membered cyclic peroxides, which are formed with sufficient internal excitation to rapidly rearrange and release oxygenated hydrocarbon radical products (Fig. 2$)^{7,18}$. In the atmosphere, these radicals rapidly react with $\mathrm{O}_{2}$ to form peroxy radicals that quickly decay to stable carbonyl products.

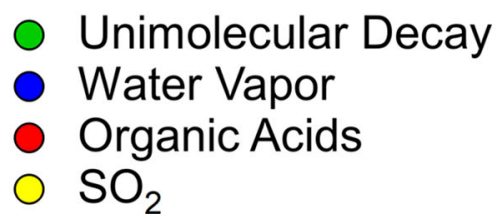

Fig. 1 Pie charts illustrating relative contributions of major atmospheric reaction pathways. The contributions of major unimolecular and bimolecular reactions for isoprene-derived Criegee intermediates $\left(\mathrm{CH}_{2} \mathrm{OO}, \mathrm{MVK}\right.$-oxide, and MACR-oxide) under tropospheric conditions predicted for the Amazon region are shown ${ }^{13,14}$. Experimental studies of anti-MACR-oxide reactions are an emerging focus ${ }^{19}$ and thus not included here.

times faster than anticipated based on analysis of chamber studies $^{1}$. Further studies demonstrated rapid reaction with organic acids-leading to functionalized hydroperoxide species via a 1,4 -addition mechanism ${ }^{11}$. By contrast, unimolecular decay of $\mathrm{CH}_{2} \mathrm{OO}$ and its bimolecular reaction with water monomers were found to be slow ${ }^{7}$. However, subsequent studies at higher water concentrations found the reaction of $\mathrm{CH}_{2} \mathrm{OO}$ with water dimers to be extremely rapid-indeed, so fast that it is predicted to dominate the removal of $\mathrm{CH}_{2} \mathrm{OO}$ from the atmosphere ${ }^{15,16}$. Theoretical and experimental studies have revealed that this reaction leads to the formation of hydroxymethyl hydroperoxide (HMHP) - a functionalized hydroperoxide species also formed from reaction of $\mathrm{CH}_{2} \mathrm{OO}$ with water monomers (see Fig. 2$)^{10}$.

\section{Bimolecular reactions of four-carbon unsaturated Criegee intermediates}

The slowly decaying conformational forms of the four-carbon unsaturated CIs, MVK-oxide (syn) and MACR-oxide (anti), can undergo bimolecular reactions with atmospherically abundant water vapor, $\mathrm{SO}_{2}$, and organic acids. Bimolecular encounters of MVK-oxide and MACR-oxide with water vapor (monomers and dimers) cause disruption of the extended conjugation in these CIs, and result in reaction barriers that are substantially higher than those for $\mathrm{CH}_{2} \mathrm{OO}^{7,12}$. This effect, along with steric hindrance arising from the substituents, dramatically reduces the predicted-and recently observed-rate coefficients for the reactions of the four-carbon unsaturated CIs with water vapor compared to $\mathrm{CH}_{2} \mathrm{OO}^{12,19}$. As a result, bimolecular reaction with water vapor is not expected to be the dominant atmospheric loss process for MVK-oxide or MACR-oxide.

By contrast, the rates coefficients for reaction of MVK-oxide with $\mathrm{SO}_{2}$ and formic acid are as large as those for $\mathrm{CH}_{2} \mathrm{OO}^{12}$. For MVK-oxide, theoretical study of its bimolecular reactions indicate that the barriers are comparatively higher than $\mathrm{CH}_{2} \mathrm{OO}$, but strongly submerged relative to reactants, such that bimolecular reaction is facile with $\mathrm{SO}_{2}$ and formic acid. Similar reaction profiles are anticipated for MACR-oxide, where rapid reaction with $\mathrm{SO}_{2}$ is also observed ${ }^{19}$.

The rapid bimolecular reactions of specific conformers of MVK-oxide and MACR-oxide with $\mathrm{SO}_{2}$ and organic acids indicates that these reactions could play important roles in the troposphere. Global modeling indicates the reaction of MVK-oxide with $\mathrm{SO}_{2}$ contributes to sulfuric acid production, ultimately 


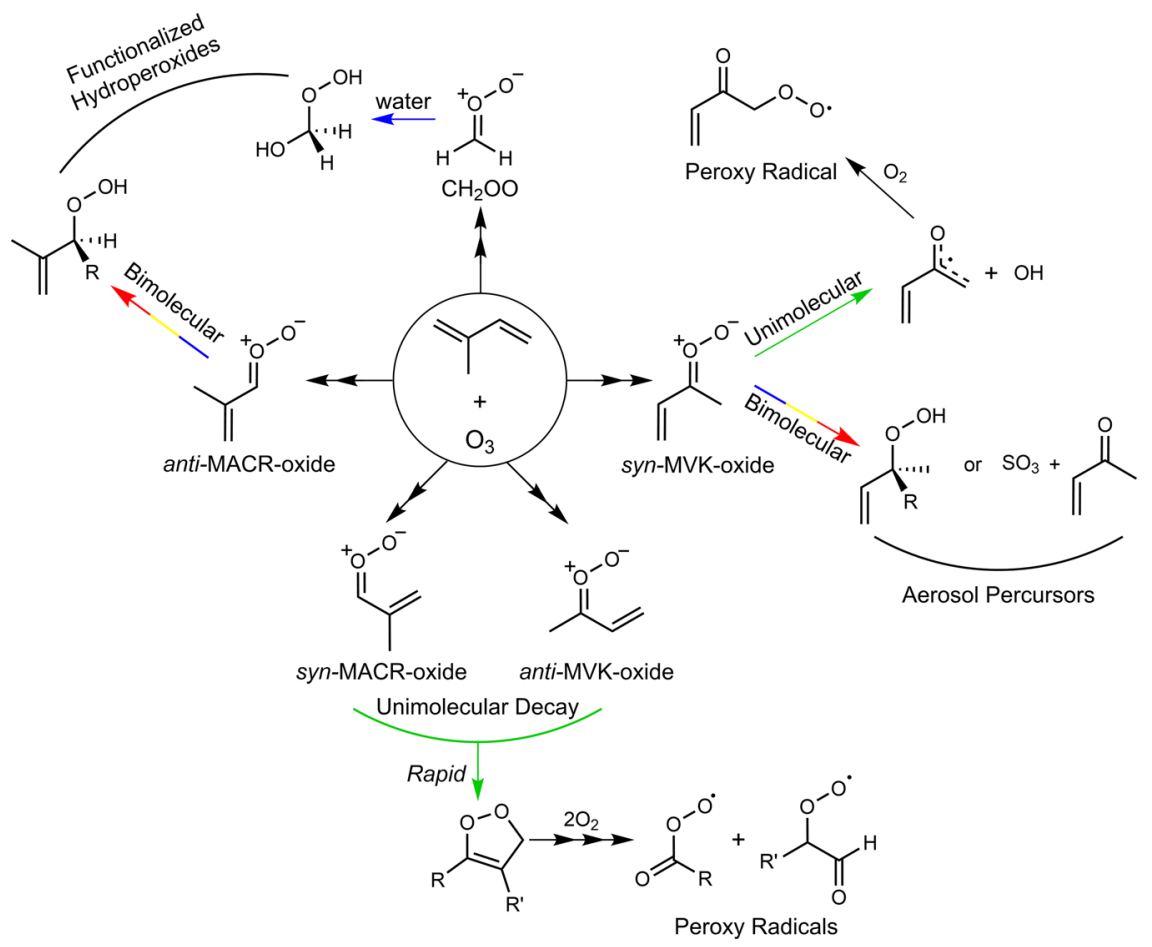

Fig. 2 Schematic illustration of major atmospheric reaction pathways. Primary unimolecular processes and bimolecular reactions for isoprene-derived Criegee intermediates $\left(\mathrm{CH}_{2} \mathrm{OO}, \mathrm{MVK}\right.$-oxide, and MACR-oxide) in the atmosphere are shown. Many of the pathways lead to reactive hydroxyl (OH) or peroxy radicals, while others involve addition reactions that generate functionalized hydroperoxides and aerosol precursors. $\mathrm{R}$ represents various substituent groups.

generating sulfate aerosols, while reaction of MVK-oxide with formic acid leads to its significant removal over the Amazon. Analogous global modeling for the bimolecular loss pathways of MACR-oxide is a future challenge.

\section{Open questions and outlook}

We anticipate that ozonolysis of many biogenic alkenes will yield more complex functionalized CIs, and that their unimolecular decay rates to $\mathrm{OH}$ radical products may be strongly impacted. Theoretical calculations and derived structure-function relationships predict new types of $\mathrm{H}$-atom migration processes for unsaturated CIs: allylic 1,4 $\mathrm{H}$-atom shift and allylic 1,6 $\mathrm{H}$-atom shift reactions ${ }^{7}$. These processes are predicted to significantly enhance $\mathrm{H}$-migration rates and enable $\mathrm{H}$-atom migration over longer ranges, thereby increasing the rates of unimolecular decay to $\mathrm{OH}$ products.

In addition, CIs with heteroatom substituents are fundamentally interesting and relatively unexplored. These CIs are important in atmospheric ozonolysis of endocyclic alkenes, such as cyclic terpenes and terpenoids with high biogenic emissions ${ }^{5}$. The ring opening associated with ozonolysis will form bifunctional CIs with carbonyl oxide and carbonyl groups, which may have a significant impact on their unimolecular and bimolecular reactivity. Moreover, new low energy pathways leading to rapid intramolecular secondary ozonide (SOZ) formation are predicted to become efficient for sufficiently large $\mathrm{CIs}^{20}$. The latter is particularly relevant for secondary organic aerosol (SOA) formation.

The role of CIs in gas-particle interconversion remains an area of significant interest. The pathways by which CIs can drive the formation of higher molecular weight, lower volatility SOA precursors, e.g., via the formation of functionalized hydroperoxides, requires further exploration. This is of particular importance for more complex and functionalized CIs including MVK-oxide and MACR-oxide, and for bimolecular reactions where functionalized hydroperoxides are formed as reaction products. For example, this occurs in reactions of CIs with water vapor, amines, alcohols, and organic acids.

There are numerous examples in the literature showing that the rate and branching fraction of gas-phase bimolecular reactions are influenced by the presence of water vapor. The influence of single water molecule complexation on the reactivity of CIs has recently been experimentally explored for the first time ${ }^{21}$. Developing a comprehensive understanding of how such complexation impacts reaction rates and product branching fractions of unimolecular and bimolecular reactions of reactive intermediates, such as the CIs formed from isoprene ozonolysis, is of significant fundamental interest and atmospheric pertinence. Furthermore, such studies will connect our current understanding of the role and reactivity of CIs in the gas phase to heterogenous environments.

Received: 5 February 2021; Accepted: 26 February 2021; Published online: 25 March 2021

\section{References}

1. Welz, O. et al. Direct kinetic measurements of Criegee intermediate $\left(\mathrm{CH}_{2} \mathrm{OO}\right)$ formed by reaction of $\mathrm{CH}_{2} \mathrm{I}$ with $\mathrm{O}_{2}$. Science 335, 204-207 (2012).

2. Cox, R. A. \& Penkett, S. A. Oxidation of atmospheric $\mathrm{SO}_{2}$ by products of the ozone-olefin reaction. Nature 230, 321-322 (1971).

3. Cox, R. A. \& Penkett, S. A. Aerosol formation from sulphur dioxide in the presence of ozone and olefinic hydrocarbons. J. Chem. Soc., Faraday Trans. 68, 1735-1753 (1972).

4. Taatjes, C. A. et al. Direct measurements of conformer-dependent reactivity of the Criegee intermediate $\mathrm{CH}_{3} \mathrm{CHOO}$. Science 340, 177-180 (2013).

5. Sindelarova, K. et al. Global data set of biogenic VOC emissions calculated by the MEGAN model over the last 30 years. Atmos. Chem. Phys. 14, 9317-9341 (2014). 
6. Nguyen, T. B. et al. Atmospheric fates of Criegee intermediates in the ozonolysis of isoprene. Phys. Chem. Chem. Phys. 18, 10241-10254 (2016).

7. Vereecken, L., Novelli, A. \& Taraborrelli, D. Unimolecular decay strongly limits the atmospheric impact of Criegee intermediates. Phys. Chem. Chem. Phys. 19, 31599-31612 (2017).

8. Barber, V. P. et al. Four-carbon Criegee intermediate from isoprene ozonolysis: Methyl vinyl ketone oxide synthesis, infrared spectrum, and $\mathrm{OH}$ production. J. Am. Chem. Soc. 140, 10866-10880 (2018).

9. Stephenson, T. A. \& Lester, M. I. Unimolecular decay dynamics of Criegee intermediates: Energy-resolved rates, thermal rates, and their atmospheric impact. Int. Rev. Phys. Chem. 39, 1-33 (2020).

10. Sheps, $\mathrm{L}$. et al. The reaction of Criegee intermediate $\mathrm{CH}_{2} \mathrm{OO}$ with water dimer: Primary products and atmospheric impact. Phys. Chem. Chem. Phys. 19, 21970-21979 (2017)

11. Chhantyal-Pun, R. et al. Criegee intermediate reactions with carboxylic acids: A potential source of secondary organic aerosol in the atmosphere. ACS Earth and Space Chem. 2, 833-842 (2018).

12. Caravan, R. L. et al. Direct kinetic measurements and theoretical predictions of an isoprene-derived Criegee intermediate. Proc. Natl. Acad. Sci. 117, 9733-9740 (2020).

13. Percival, C. J. et al. Regional and global impacts of Criegee intermediates on atmospheric sulphuric acid concentrations and first steps of aerosol formation. Faraday Discuss 165, 45-73 (2013).

14. Khan, M. A. H. et al. Changes to simulated global atmospheric composition resulting from recent revisions to isoprene oxidation chemistry. Atmos. Environ. 244, 117914 (2021).

15. Chao, W., Hsieh, J.-T., Chang, C.-H. \& Lin, J. J.-M. Direct kinetic measurement of the reaction of the simplest Criegee intermediate with water vapor. Science 347, 751-754 (2015).

16. Lewis, T. R., Blitz, M. A., Heard, D. E. \& Seakins, P. W. Direct evidence for a substantive reaction between the Criegee intermediate, $\mathrm{CH}_{2} \mathrm{OO}$, and the water vapour dimer. Phys. Chem. Chem. Phys. 17, 4859-4863 (2015).

17. Vansco, M. F. et al. Synthesis, electronic spectroscopy and photochemistry of methacrolein oxide: A four carbon unsaturated Criegee intermediate from isoprene ozonolysis. J. Am. Chem. Soc. 141, 15058-15069 (2019).

18. Vansco, M. F. et al. Experimental evidence of dioxole unimolecular decay pathway for isoprene-derived Criegee intermediates. J. Phys. Chem A 124, 3542-3554 (2020).

19. Lin, Y.-H., Yin, C., Takahashi, K. \& Lin, J. J.-M. Surprisingly long lifetime of methacrolein oxide, an isoprene derived Criegee intermediate, under humid conditions. Commun. Chem. 4, 12 (2021).

20. Long, B., Bao, J. L. \& Truhlar, D. G. Rapid unimolecular reaction of stabilized Criegee intermediates and implications for atmospheric chemistry. Nat. Comm. 10, 2003 (2019).

21. Chao, W., Yin, C. T., Takahashi, K. \& Lin, J. J. M. Hydrogen-bonding mediated reactions of Criegee intermediates in the gas phase: Competition between bimolecular and termolecular reactions and the catalytic role of water. J. Phys. Chem A 123, 8336-8348 (2019).

\section{Acknowledgements}

M.I.L. acknowledges partial support for research conducted at the University of Pennsylvania by the U.S. Department of Energy - Basic Energy Sciences under grant DEFG02-87ER13792 and the National Science Foundation under grants CHE-1955068 and CHE-1664572. R.L.C. and M.F.V. acknowledge support at Argonne National Laboratory by the U.S. Department of Energy, Office of Science, Office of Basic Energy Sciences, Division of Chemical Sciences, Geosciences, and Biosciences under Contract No. DEAC02-06CH11357. This research used resources of the Advanced Light Source, a U.S. DOE Office of Science User Facility under contract no. DE-AC02-05CH11231. M.I.L. and R.L.C. thank senior collaborators Craig A. Taatjes (Sandia National Laboratories), Stephen J. Klippenstein (Argonne National Laboratory), Carl J. Percival (NASA Jet Propulsion Laboratory), Dudley E. Shallcross (University of Bristol), M. Anwar H. Khan (University of Bristol), and many talented graduate students and postdoctoral researchers who contributed to this work.

\section{Author contributions}

M.I.L, R.L.C., and M.F.V. all contributed to the preparation of this manuscript.

\section{Competing interests}

The authors declare no competing interests.

\section{Additional information}

Correspondence and requests for materials should be addressed to M.I.L.

Reprints and permission information is available at http://www.nature.com/reprints

Publisher's note Springer Nature remains neutral with regard to jurisdictional claims in published maps and institutional affiliations.

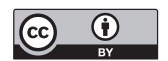

Open Access This article is licensed under a Creative Commons Attribution 4.0 International License, which permits use, sharing, adaptation, distribution and reproduction in any medium or format, as long as you give appropriate credit to the original author(s) and the source, provide a link to the Creative Commons license, and indicate if changes were made. The images or other third party material in this article are included in the article's Creative Commons license, unless indicated otherwise in a credit line to the material. If material is not included in the article's Creative Commons license and your intended use is not permitted by statutory regulation or exceeds the permitted use, you will need to obtain permission directly from the copyright holder. To view a copy of this license, visit http://creativecommons.org/ licenses/by/4.0/.

(C) The Author(s) 2021 